\title{
Separation and recovery of critical metal ions using ionic liquids
}

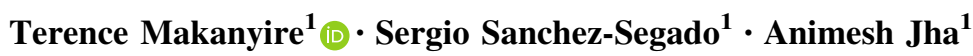

Received: 6 July 2015/ Accepted: 16 December 2015/Published online: 2 March 2016

(c) The Author(s) 2016. This article is published with open access at Springerlink.com

\begin{abstract}
Separation and purification of critical metal ions such as rare-earth elements (REEs), scandium and niobium from their minerals is difficult and often determines if extraction is economically and environmentally feasible. Solvent extraction is a commonly used metal-ion separation process, usually favored because of its simplicity, speed and wide scope, which is why it is often employed for separating trace metals from their minerals. However, the types of solvents widely used for the recovery of metal ions have adverse environmental impact. Alternatives to solvent extraction have been explored and advances in separation technologies have shown commercial establishment of liquid membranes as an alternative to conventional solvent extraction for the recovery of metals and other valuable materials. Liquid membrane transport incorporates solvent extraction and membrane separation in one continuously operating system. Both methods conventionally use solvents that are harmful to the environment, however, the introduction of ionic liquids (ILs) over the last decade is set to minimize the environmental impact of both solvent extraction and liquid membrane separation processes. ILs are a family of organic molten salts with low or negligible vapour pressure which may be formed below $100{ }^{\circ} \mathrm{C}$. Such liquids are also highly thermally stable and less toxic. Their ionic structure makes them thermodynamically favorable solvents for the extraction of metallic ions. The main aim of this article is to review the current achievements in the separation of REE, scandium, niobium and vanadium from their minerals, using ILs in either
\end{abstract}

Terence Makanyire

pmtm@leeds.ac.uk

1 Institute for Materials Research, University of Leeds, Leeds LS2 9JT, UK solvent extraction or liquid membrane processes. The mechanism of separation using ILs is discussed and the engineering constraints to their application are identified.

Keywords Critical metals - Ionic liquids (ILs) ·

Niobium · Tantalum · Rare-earth elements (REEs) ·

Vanadium $\cdot$ Scandium

\section{Introduction}

The European Commission published a report in July 2010 identifying a number of raw materials as "critical" to Europe's economy [1]. "Critical" raw materials are those for which the supply into the European Union (EU) is under threat due to the rapid increase in demand and current geopolitical situations. Without supply security, the EU economy will be severely undermined. Niobium and the rare-earth elements (REEs) are into this classification because of their low substitution rate and their key role in important economic sectors.

The energy required for refining these metals is shown in Fig. 1. Up to $30 \%$ of the energy required is employed in separation processes such as solvent extraction $[2,3]$. In this review article, the latest developments in extractive technologies of vanadium, niobium, tantalum and REEs are presented.

\subsection{Rare-earth sources}

The REEs are a group of fifteen elements, including yttrium, belonging to the lanthanide series, with unique properties which make them essential for the development of green and energy efficient technologies [4]. According to the International Union of Applied and Pure Chemistry 

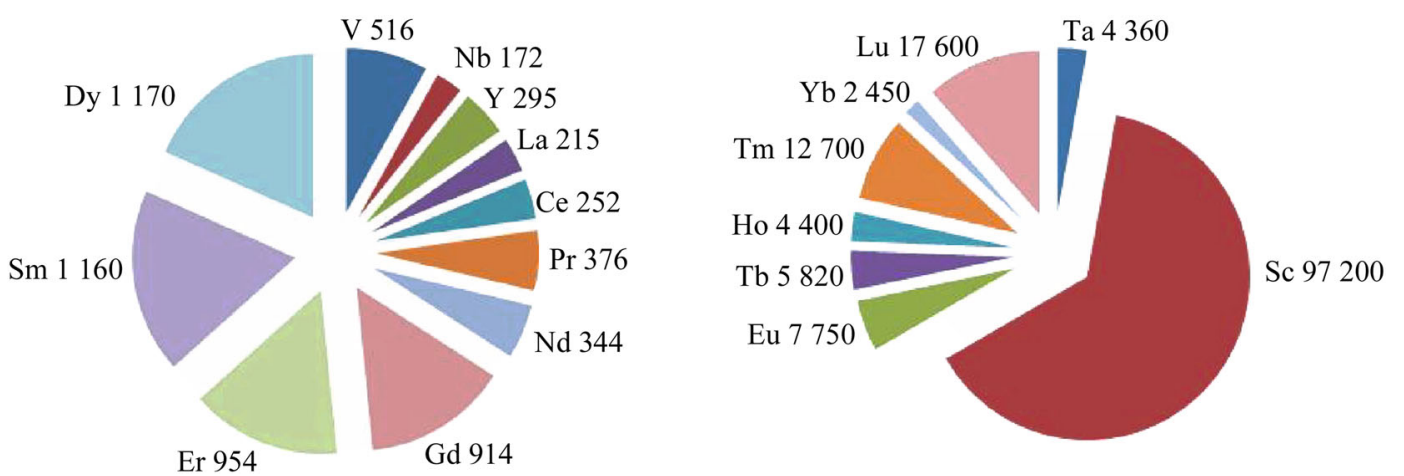

Fig. 1 Cumulative energy demand (MJ/kg) for the extraction and processing of selected rare-earth metals [2] (The comparable energy demand for iron and steel is less than 100-1 000 times (typically below $30 \mathrm{GJ} / \mathrm{t}$ or $30 \mathrm{MJ} / \mathrm{kg}$ ).)

(IUPAC) [5], the REEs can be classified into light rareearths (LREs) (lanthanum, cerium, praseodymium, neodymium, promethium and samarium) and heavy rare-earths (HREs) (europium, gadolinium, terbium, dysprosium, holmium, erbium, thulium, ytterbium and lutetium). Despite being called REEs, these elements are not so rare in terms of crustal abundance, nevertheless, because of their wide distribution in low concentrations (nearly 200 minerals with less than $0.01 \%$ are known) and the difficulties associated with their extraction, they are considered rare [6]. The minerals which are currently commercially exploited are shown in Fig. 2 [7, 8].

By comparison, scandium is a pre-lanthanide element with lower atomic mass than the rare-earth lanthanide series. However, due to its comparable electronic structure, its chemical properties determine its mineral association with the REEs. In this review, the scandium is included as it is distributed sparsely in trace amounts in rocks consisting of ferromagnesian minerals with an abundance of $(5-100) \times 10^{-6}[9]$. This is because the $3+$ valance state and ionic size permit substitution with iron and aluminium

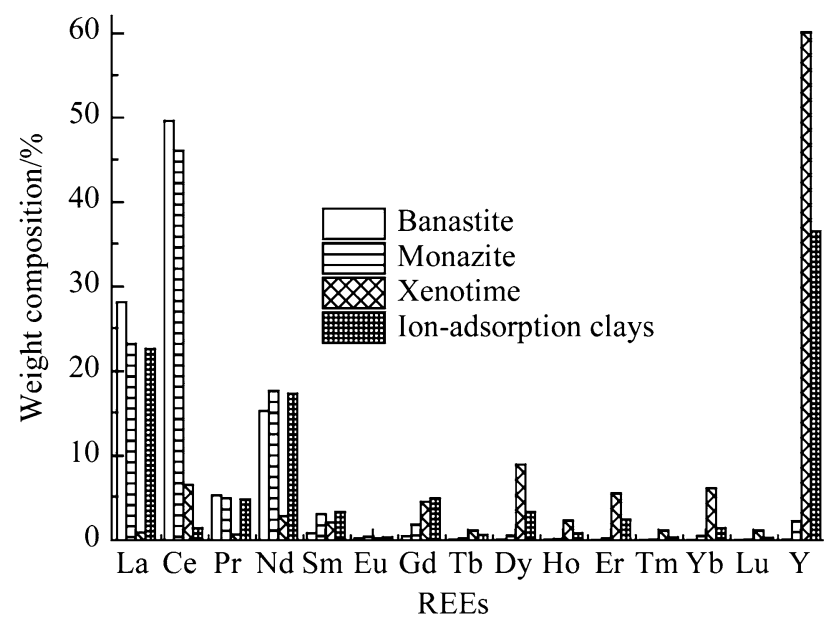

Fig. 2 Average rare-earth distribution in commercial rare-earth minerals (\% of total rare-earth oxides (REOs)) [6-8] in minerals and therefore justifies its mineralogical co-existence. Ore bodies which are considered worthy of exploitation have a scandium concentration in the range of $(2-5) \times 10^{-5}$ [9], where it can be recovered as a by-product from residues, tailings and waste liquors during production of other metals such as rare-earths, aluminium and niobium. Red mud produced in Greece and Jamaica has been reported to contain $(1.05-1.72) \times 10^{-4}$ scandium, and therefore contain enough scandium for consideration as a secondary source [10-12].

The main commercial uses of REEs and scandium are summarized in Fig. 3.

Global production of scandium is believed to be of the order of $10 \mathrm{t}$ per year. However the demand prognosis suggests that, if more becomes available, the demand in energy sector will increase.

The REEs can be recycled from end-life products such as permanent magnets ( $\mathrm{Nd}, \mathrm{Dy}, \mathrm{Tb}, \mathrm{Pr})$, fluorescent lamps, phosphors (Eu, Tb, Y, Ce, Gd, La), nickel batteries (La, Ce, $\mathrm{Nd}, \mathrm{Pr}$ ) and other industrial wastes; for example red mud and phosphogypsum using different pyro and hydrometallurgical approaches [14]. Scandium can also be recycled from aluminium alloys at the end of its use. However, less than $1 \%$ of the REEs and scandium are recycled in the economy at present due to inefficient collection, technological issues of extraction of such elements in end-life products and industrial wastes. Furthermore, in general there is a lack of initiatives for recycling electronic wastes and end-of-life products where valuable metal concentrations are much higher than that in the natural environments $[13,14]$.

\subsection{Niobium and tantalum sources}

Niobium has been included on the list of 20 most critical raw materials in Europe due to the risk in the security of supply and economic importance [1]. Niobium is widespread worldwide but rarely accumulates in concentrations 


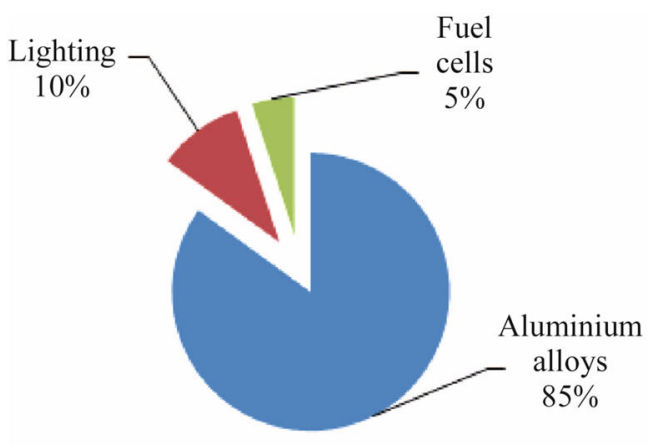

(a) Usages of scandium

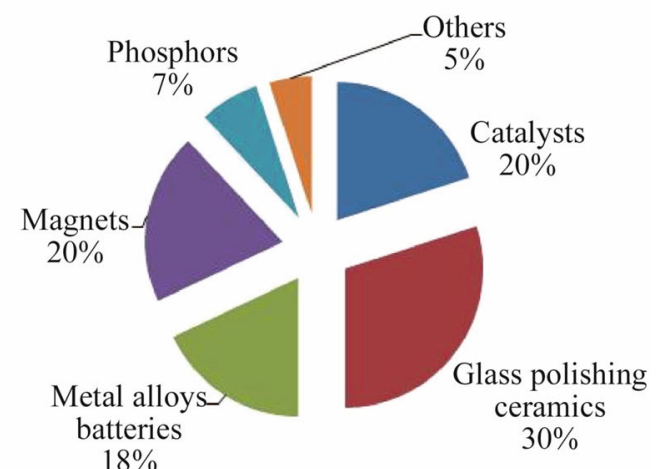

(b) Uses of REEs

Fig. 3 Usages of scandium and REEs in 2011 [13]

high enough for economic mining. Brazil has about $92 \%$ of global production, with Canada and Nigeria supplying the remaining 8\% [15]. Almost all reserves are located in Brazil, with less than 5\% located in Canada [15]. In the USA, more than $150000 \mathrm{t}$ of niobium resources have been identified [1]. And in Europe, niobium and tantalum deposits have been identified in Finland and Norway, but are not economic to exploit using conventional processes $[1,16]$.

The similarity in electronic structures of niobium and tantalum means that they are almost always found together in nature and require similar processes for extraction and purification, and can be substituted for one another for certain applications. Niobium and tantalum are components of hundreds of different minerals, which mainly consist of complex salts of niobic and tantalic acid together with titanium, zirconium, tin, REE, thorium, uranium and alkaliearth metals in variable ratios [17]. The most important mineral sources of niobium and tantalum may be classified as: (i) Tantalo-niobates-salts of niobic and tantalic acids such as columbite and tantalite; (ii) Titano(tantalo)-niobates in which titanium is the main component associated with niobium, tantalum and lanthanides.

In Fig. 4, the chemical composition of the main tantalum and niobium minerals is presented. Tantalite and columbite are the main sources for industrial production of tantalum and niobium, respectively [8].

The main applications of niobium and tantalum are presented in Figs. 5 and 6.

High strength low alloy steels consume most of the niobium as ferroniobium [18]. The steels are used in construction, oil and gas pipelines, and automotive industry. Niobium also has usage in special alloys for the nuclear and aircraft industries, magnets, superconductors, capacitors and catalysts. Demand for ferroniobium is set to increase, with a forecast of $8 \%$ per year [1]. This is driven mainly by the strong global demand for steel in

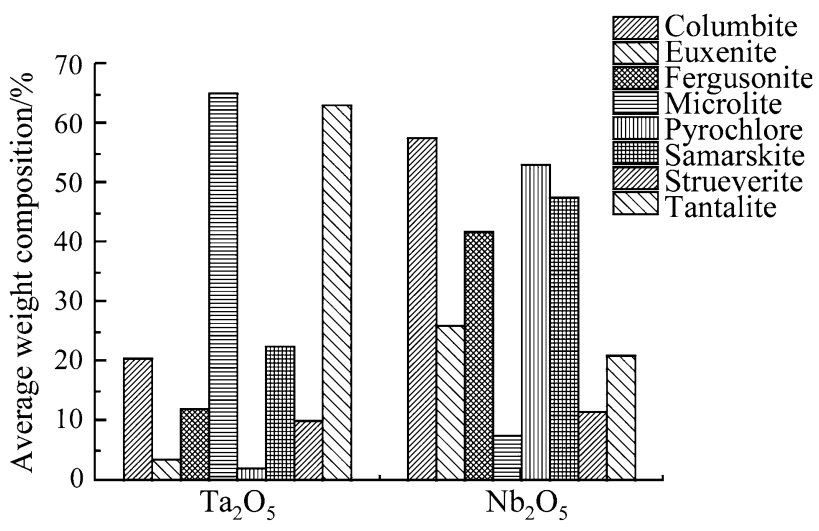

Fig. 4 Average niobium and tantalum oxides distribution in industrial minerals [8]

construction, infrastructure and automotive applications. The major use for tantalum, as the metal powder, is in the production of electronic components, mainly capacitors and some high-power resistors. Because of the size and weight advantages, tantalum capacitors are attractive for portable telephones, personal computers, and automotive electronics [1]. Tantalum is also used to produce a variety of alloys that have high melting points, strength, and ductility for making carbide tools for metal-working equipment, superalloys for jet engine components, equipment with high corrosion resistance, nuclear reactors, missile parts, surgical instruments and implants.

The US Geological Survey has estimated that tantalum and niobium recycling rates are around 20\% [19]. Tantalum is recycled from waste and scrap like old cell phones and computers. Meanwhile, ferroniobium and niobium alloys are the main recycling sources for niobium [19].

\subsection{Vanadium sources}

Although not classed as critical in Europe, vanadium was classed as the raw material with the highest economic 


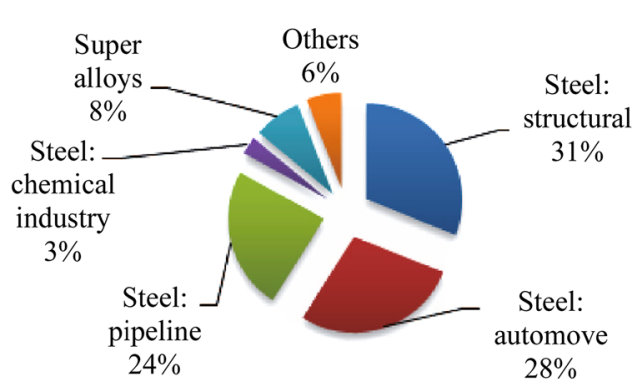

(a) Global end-use of niobium

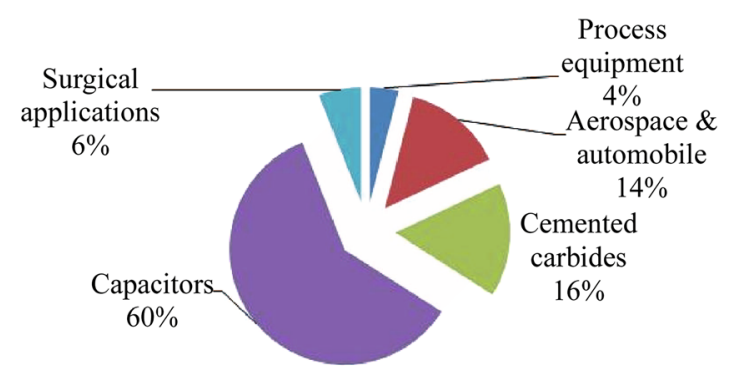

(b) Global-end use of tantalum

Fig. 5 Global end-uses of niobium and tantalum in 2010 [18]

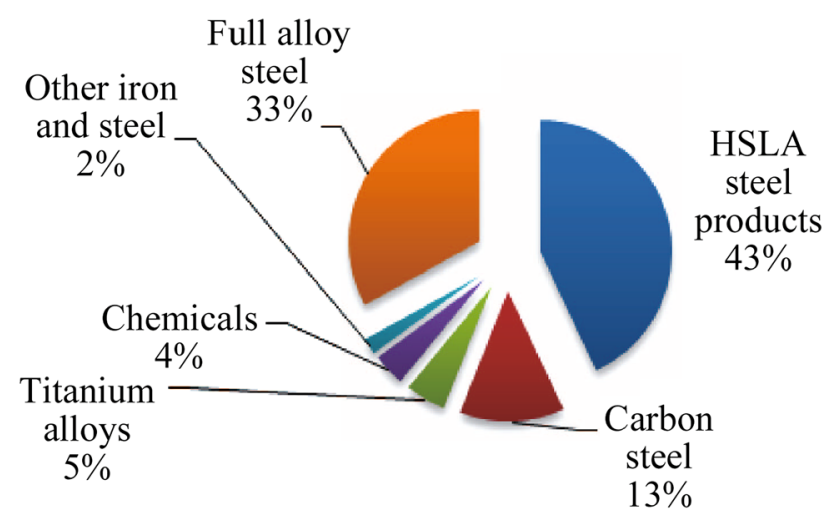

Fig. 6 Global end-use of vanadium in 2012 [20]

importance among the fifty-four candidate materials [1]. It was not considered critical due to the low risk in supply security. Like scandium, vanadium is primarily produced as a by-product, usually from the processing of titaniferousmagnetites, mineral oils, uranium-vanadium ores, phosphates and bauxites.

About $90 \%$ of the global end-use of vanadium is in the steel industry, with majority of the remaining $10 \%$ split between production of chemicals and titanium alloys [20].

Several processes for vanadium recovery and recycling have been developed. The Mineral Commodity Summaries by the US Geological Survey concluded that tool steel scrap and spent vanadium containing catalysts constitute up to $40 \%$ of global vanadium supply [21].

\section{Solvent extraction}

Solvent extraction is a well-established technique used in various chemical industries for producing pure chemical compounds including pharmaceuticals, heavy organics and metals, based on the fundamental physical chemistry of solvent-solute interaction, activity factors of the solutes in the pure phases, aqueous complexation and complex- adduct interactions [22]. Most processes for separation and purification of REEs generally employ solvent extraction techniques, using two immiscible liquid phases to obtain a two-phase distribution of the metal ions.

\subsection{Ionic liquids (ILs)}

ILs are organic salts consisting of an organic cation and, commonly but not always, an inorganic anion. One of the main characteristics of these compounds is their low melting points (generally below $100{ }^{\circ} \mathrm{C}$ ) in comparison with molten salts having melting points higher than $300{ }^{\circ} \mathrm{C}$. The low melting points can be explained from the potential energy of interaction between ions (see Eq. (1)) [23]:

$$
E=\frac{M}{4 \pi \varepsilon_{0}} \frac{Z^{+} Z^{-}}{d},
$$

where $Z^{+}$and $Z^{-}$are the charges of the ions, $M$ the Madelung constant, $\varepsilon_{0}$ the vacuum permittivity, and $d$ the interionic distance in nanometres. An increase in the interionic distance, a lower packing efficiency (denoted by the Madelung constant), and a lower charge density is interpreted as lower lattice energy, hence lower melting point. In Table 1, the Madelung constant values of some ILs are compared with common inorganic salts.

In Fig. 7, ILs are formed by big asymmetrical ions with diffuse charge density.

These ion combinations endow ILs with interesting properties such as low vapour pressure and flammability, high dissolution power for organic and inorganic compounds, wide electrochemical windows and high thermal stability [26]. From the point of view of solvent extraction, the most important property is their water solubility because it will determine environmental and economic management related issues. The hydrophobicity of the ILs is determined by the anion. Regel-Rosocka and Wisniewski [27] proposed the following anion arrangement according to increasing hydrophobicity: 
Table 1 Madelung constant values of organic and inorganic salts [24]

\begin{tabular}{|c|c|c|c|}
\hline Salt & Melting point $/{ }^{\circ} \mathrm{C}$ & Crystal type & Madelung constant \\
\hline $\mathrm{CaF}_{2}$ & 1418 & Cubic & 2.524 \\
\hline $\mathrm{CaCl}_{2}$ & 772 & Cubic & 2.364 \\
\hline $\mathrm{NaCl}$ & 801 & Cubic & 1.474 \\
\hline$\left[\mathrm{C}_{1} \mathrm{mpyr}\right]\left[\mathrm{Tf}_{2} \mathrm{~N}\right]$ & 132 & Monoclinic & 1.358 \\
\hline$\left[\mathrm{C}_{2} \mathrm{mpyr}\right][\mathrm{TsO}]$ & 120 & Monoclinic & 1.408 \\
\hline$\left[\mathrm{C}_{4} \mathrm{mpyr}\right][\mathrm{TsO}]$ & 115 & Triclinic & 1.296 \\
\hline$\left[\mathrm{C}_{4} \operatorname{mim}\right][\mathrm{Cl}]$ & 66 & Orthorhombic & 1.379 \\
\hline$\left[\mathrm{C}_{4} \operatorname{mim}\right][\mathrm{Cl}]$ & 41 & Monoclinic & 1.345 \\
\hline$\left[\mathrm{C}_{4} \mathrm{mpyr}\right]\left[\mathrm{Tf}_{2} \mathrm{~N}\right]$ & -18 & Orthorhombic & 1.285 \\
\hline
\end{tabular}

Cations<smiles></smiles><smiles></smiles><smiles>[R16]C([R16])=[N+]=[R16]</smiles>

Anions

$$
\begin{array}{lllll}
\mathrm{Cl}^{\ominus} & \mathrm{Br}^{\ominus} & \mathrm{TsO}^{\ominus} & \mathrm{BF}_{1}^{\ominus} & \mathrm{PF}_{6}^{\ominus} \\
\mathrm{CN}^{\ominus} & \mathrm{N}_{3}^{\ominus} & \mathrm{TfO}^{\ominus} & \mathrm{Tf}_{2} \mathrm{~N}^{\ominus} & (\mathrm{CN})_{2} \mathrm{~N}^{\ominus} \\
\mathrm{AcO}^{\ominus} & \mathrm{CF}_{3} \mathrm{CO}_{2}^{\ominus} & \mathrm{NO}_{3}^{\ominus} & \mathrm{ClO}_{4}^{\ominus} \\
\mathrm{FeCl}_{4}^{\ominus} & \mathrm{AlCl}_{4}^{\ominus} & \mathrm{Al}_{2} \mathrm{Cl}_{7}^{\ominus} & \mathrm{TiCl}_{6}{ }^{2 \ominus}
\end{array}
$$

Fig. 7 ILs structures [25] (Abbreviations have the following meanings: $R^{1}$ and $R^{2}$ represent linear organic chains, $\mathrm{Tf}_{2} \mathrm{~N}=$ bis(trifluoromethylsulfonyl)imide, $\quad \mathrm{TsO}=$ tosylate,$\quad \mathrm{TfO}=$ trifluoromethasulfonate, $\mathrm{AcO}=$ acetate.)

$$
\mathrm{N}\left(\mathrm{SO}_{2} \mathrm{CF}_{2} \mathrm{CF}_{3}\right)_{2}^{-}>\mathrm{N}\left(\mathrm{SO}_{2} \mathrm{CF}_{3}\right)_{2}^{-}>\mathrm{CF}_{3} \mathrm{SO}_{3}^{-}>\mathrm{PF}_{6}^{-}
$$$$
>\mathrm{BF}_{4}^{-}>\mathrm{ClO}_{4}^{-}>\mathrm{CuCl}_{2}^{-}>\mathrm{Br}^{-}>\mathrm{Cl}^{-}>\mathrm{NO}_{3}^{-}
$$

Moreover, the hydrophobicity also depends on the chemical and physical factors like the temperature. The ILs based on imidazolium cations are more water soluble with an increase of temperature, nonetheless, the presence of alkali chlorides in the aqueous solution decreases the solubility. Dilution of the ILs in organic compounds also affects the water solubility of the ILs. For example, the dilution of imidazolium ILs in tri- $n$-butyl-phosphate increases its water solubility [25-27].

ILs have been classed as green solvents for a long time because their low vapour pressure removes one exposition pathway, decreasing health impairments. However, recent studies have put into manifest that some ILs have remarkably toxic effects across organisms and trophic levels [28].

The main feature in toxicity of ILs is the "alkali chain side effect", which is strongly related to their cationic part. An increase in the alkali chain length or hydrophobicity has proven to increase the toxicity and biodegradability of the ILs. On the other hand, the introduction of functional polar groups in the alkali chains enhances the biodegradability and reduces the toxicity [29]. Regarding the anionic part, only per-fluorinated anions and $\left[\mathrm{N}\left(\mathrm{SO}_{2} \mathrm{CF}_{3}\right)_{2}^{-}\right]$show ecotoxicological properties [28, 29].

\subsection{Extraction mechanisms}

The extraction of metallic ions, using conventional organic solvents, has been studied for decades, and the main extraction agents and the mechanisms are described below $[6,8,30]$.

\subsubsection{Acid extractants}

Acid extractants follow a cation exchange extraction mechanism which involves displacement of a hydrogen ion from the extractant by the extracted metal, forming a neutral organic soluble complex. Acid extractants commonly used are, phosphoric, phosphonic and carboxylic acids $\left(\mathrm{C}_{7}-\mathrm{C}_{15}\right)$. They exist in dimeric form $\left(\mathrm{H}_{2} \mathrm{~A}_{2}\right)$ when dissolved in organic solvents of low polarity, therefore, the extraction can be represented by reaction (2).

$\mathrm{M}_{(\mathrm{a})}^{n+}+3 \mathrm{H}_{2} \mathrm{~A}_{2(\mathrm{o})} \leftrightarrow \mathrm{M}\left(\mathrm{HA}_{2}\right)_{n(\mathrm{o})}+3 \mathrm{H}_{(\mathrm{a})}^{+}$

where (a) and (o) are the species present in aqueous and organic phases, respectively.

\subsubsection{Solvating extractants}

When using solvating extractants, the extractant partly or fully removes some of the water molecules from the 
hydrated metallic ion to increase its solubility in the organic phase. One of the commonest solvating extractants is tri-butyl-phosphate (TBP). For most extraction processes employing TBP, the extraction mechanism is given as

$$
\begin{aligned}
& {\left[\mathrm{M}\left(\mathrm{NO}_{3}\right)_{n} \cdot x \mathrm{H}_{2} \mathrm{O}\right]_{(\mathrm{a})}+n[\mathrm{TBP}]_{(\mathrm{o})}} \\
& \quad \leftrightarrow\left[\mathrm{M}\left(\mathrm{NO}_{3}\right)_{n}(\mathrm{TBP})_{n}\right]_{(\mathrm{o})}+x \mathrm{H}_{2} \mathrm{O}_{(\mathrm{a})} .
\end{aligned}
$$

\subsubsection{Basic extractants}

Basic extractants remove metallic ions from aqueous solutions as anionic complexes by anion exchange. Long chain amines belong to this type of extractants. Extraction mechanism in thiocyanate, nitrate and sulphate media are shown in reactions (4)-(6), where $R_{4}$ represents $C_{8}$ to $C_{12}$ :

$$
\begin{aligned}
& {\left[\mathrm{M}(\mathrm{NCS})_{n}\right]_{(\mathrm{a})}+\left[\mathrm{R}_{4} \mathrm{~N} \cdot \mathrm{NCS}\right]_{(\mathrm{o})}} \\
& \leftrightarrow\left[\mathrm{R}_{4} \mathrm{~N} \cdot \mathrm{M}(\mathrm{NCS})_{\mathrm{n}+1}\right]_{(\mathrm{o})}, \\
& {\left[\mathrm{M}(\mathrm{NO})_{n}\right]_{(\mathrm{a})}+\left[\mathrm{R}_{4} \mathrm{~N} \cdot \mathrm{NO}_{3}\right]_{(\mathrm{o})}} \\
& \leftrightarrow\left[\mathrm{R}_{4} \mathrm{~N} \cdot \mathrm{M}\left(\mathrm{NO}_{3}\right)_{n+1}\right]_{(\mathrm{o})} \\
& {\left[\mathrm{M}\left(\mathrm{SO}_{4}\right)_{n}\right]_{(\mathrm{a})}+\left[\mathrm{R}_{4} \mathrm{~N} \cdot \mathrm{SO}_{4}\right]_{(\mathrm{o})}} \\
& \leftrightarrow\left[\mathrm{R}_{4} \mathrm{~N} \cdot \mathrm{M}\left(\mathrm{SO}_{4}\right)_{n+1}\right]_{(\mathrm{o})}
\end{aligned}
$$

Reactions (4) to (6) show that the first step of the extraction process involves the formation of an organic salt.

The extraction mechanisms in ILs are of cationic or anionic exchange nature, and less frequently, solvation of the metallic species. These mechanisms have been observed in imidazolium, ammonium and phosphonium ILs. Some examples are shown in reactions (7) to (9) [31-36]:

$$
\begin{aligned}
& \mathrm{M}_{(\mathrm{a})}^{m+}+m \mathrm{TODGA}_{(\mathrm{o})}+m\left[\mathrm{C}_{n} \mathrm{mim}^{+}\right]_{(\mathrm{o})} \\
& \leftrightarrow \operatorname{MTODGA}_{3(\mathrm{o})}^{\mathrm{m}+}+m\left[\mathrm{C}_{n} \mathrm{mim}^{+}\right]_{(\mathrm{a})}, \\
& \mathrm{M}_{(\mathrm{a})}^{n+}+(n+1) \mathrm{Htta}_{(\mathrm{o})}+\left[\mathrm{C}_{4} \mathrm{mim}^{+}\right]\left[\mathrm{N}\left(\mathrm{SO}_{2} \mathrm{CF}_{3}\right)_{2}^{-}\right]_{(\mathrm{o})} \\
& \leftrightarrow\left[\mathrm{C}_{4} \operatorname{mim}\right]\left[\mathrm{M}(\mathrm{tta})_{n+1}\right]_{(\mathrm{o})}+n+1\left[\mathrm{H}^{+}\right]_{(\mathrm{a})} \\
& +\left[\mathrm{N}\left(\mathrm{SO}_{2} \mathrm{CF}_{3}\right)_{2}^{-}\right]_{(\mathrm{a})} \text {, } \\
& 2 \mathrm{M}_{(\mathrm{a})}^{n+}+n[\mathrm{~A} 336][\mathrm{Bis}]_{(\mathrm{o})}+2 n \mathrm{NO}_{3(\mathrm{a})}^{-} \\
& \leftrightarrow[\mathrm{A} 336]\left[\mathrm{M}\left(\mathrm{NO}_{3}\right)_{n} \mathrm{Bis}\right]_{(\mathrm{o})}+n[\mathrm{~A} 336]\left[\mathrm{NO}_{3}\right]_{(\mathrm{o})} \\
& +\left[\mathrm{M}\left(\mathrm{NO}_{3}\right)_{n-1} \mathrm{Bis}\right]_{(\mathrm{o})} \\
& \mathrm{M}_{(\mathrm{a})}^{n+}+n \mathrm{R}_{4} \mathrm{NCy}+\mathrm{SO}_{4(\mathrm{a})}^{2-} \leftrightarrow \mathrm{MCy}_{n(\mathrm{o})}+\left(\mathrm{R}_{4} \mathrm{~N}\right)_{n}\left[\mathrm{SO}_{4}\right]_{(\mathrm{a})},
\end{aligned}
$$

where TODGA is $\left(\mathrm{N}, \mathrm{N}, \mathrm{N}^{\prime}, \mathrm{N}^{\prime}\right.$-tetra(octyl)diglycolamide; $\mathrm{C}_{n}$ mim is the $n$-alkyl-methylimidazolium-cation; $\mathrm{Htta}$ is 1-(2-thienyl)-4,4,4-trifluoro-1,3-butanedione; [A336][Bis] is tri-n-octyl-methyl ammoniumbis(2,4,4-trimethylpentyl) phosphinate; $\left[\mathrm{P}_{66614}\right][\mathrm{MA}]$ is tri-hexyl (tetradecyl) phosphonium $\mathrm{N}, \mathrm{N}, \mathrm{N}^{\prime}, \mathrm{N}^{\prime}$-tetra(2-ethylhexyl)malonamide and $\mathrm{R}_{4} \mathrm{NCy}$ is the general form of a quaternary ammonium based ionic liquid. The contamination of the aqueous phase by the components of the ionic liquid in some cases (reactions (7), (8)) may be a limitation for their applicability in solvent extraction systems. However, new developments in organic synthesis are promoting ILs which mainly recover metallic ions by solvation mechanisms [37]. Castillo et al. [38] used dicarboxylic acids as anions for the extraction of divalent ions $(\mathrm{Cd}, \mathrm{Cu}$ and $\mathrm{Pb})$ from neutral aqueous systems via an ion exchange mechanism and their water-immiscible-halogen-free ILs minimised loss of the ILs into the aqueous phase.

\subsection{Solvent extraction processes applied for the recovery of rare earths}

The separation of REEs has been widely investigated using various types of extraction agents. Carboxylic acids such as naphthenic acid are used for the separation of yttrium from the rest of lanthanides elements. However, problems associated with compositional changes of the extraction agent and high water solubility, promoted the use of lower water solubility acids like sec-nonylphenoxy acetic acid (CA-100) and sec-octylphenoxy acetic acid (CA-12) [39]. Organophosphorous acids such as asdi-2-ethylhexylphosphoric acid (D2EHPA) diluted in toluene have been used for extracting REEs from hydrochloric solutions. The selectivity order follows the sequence $\mathrm{Lu}>\mathrm{Yb}>$ $\mathrm{Tm}>\mathrm{Tb}>\mathrm{Eu}>\mathrm{Pm}>\mathrm{Pr}>\mathrm{Ce}>$ La. Preston et al. [4042] developed a continuous process for separating $\mathrm{Sm}, \mathrm{Eu}$, $\mathrm{Gd}$, and $\mathrm{Tb}$ from $\mathrm{La}, \mathrm{Ce}, \mathrm{Pr}$, and $\mathrm{Nd}$ in nitrate media. The first group was extracted using an eight counter-current stage system loaded with $15 \%$ (volume ratio) D2EHPA diluted in Shellsol AB organic phase. The organic phase was scrubbed with $1 \mathrm{~mol} / \mathrm{L}^{\mathrm{HNO}_{3}}$ solution (2-4 stages) and the REEs were stripped with $1.5 \mathrm{~mol} / \mathrm{L} \mathrm{HCl}$ solution in 6-8 stages. Dy with some $\mathrm{Tb}$ and Gd was removed with $2.5 \mathrm{~mol} / \mathrm{L} \mathrm{HCl}$ solution in a secondary stripping of four stages. Although D2EHPA allows the REEs extraction at low $\mathrm{pH}$, the recovery of the extracted metals is quite difficult due to that the prevalent chemical equilibrium existing between the aqueous and organic phases demands very acidic stripping solutions [43]. HEHEHP (2-ethylhexyl phosphonic acid mono-2-ethylhexyl), can be used to strip REEs at lower acidities compared to D2EHPA [44]. The extraction of REEs in chloride and nitrate media follows the sequence $\mathrm{La}<\mathrm{Ce}<\mathrm{Pr}<\mathrm{Nd}<\mathrm{Sm}<\mathrm{Eu}<$ $\mathrm{Gd}<\mathrm{Tb}<$ Dy $(\mathrm{Y})<\mathrm{Ho}<\mathrm{Er}<\mathrm{Tm}<\mathrm{Yb}<$ Lu [44].

Sun et al. [45] studied the separation of rare-earth ions using the functionalized ILs tetrabutylammonium di(2ethylhexyl)phosphate [TBA][DEHP], tri- $n$-octylmethylammonium di(2-ethylhexyl)phosphate [A336][DEHP] and trihexyl(tetradecyl)phosphonium [THTP][DEHP], diluted in $\left[\mathrm{C}_{6} \mathrm{mim}\right]\left[\mathrm{NTf}_{2}\right]$ or diisopropylbenzene (DIPB). They 
found that the extraction efficiency was higher for those dissolved in $\left[\mathrm{C}_{6} \mathrm{mim}\right]\left[\mathrm{NTf}_{2}\right]$ with relative distribution coefficients 100 times higher. They also reported a selectivity increase for HRRE, when compared with the conventional system using di(2-ethylhexyl)phosphoric acid (HDEHP) dissolved in the same diluents. Yang et al. [46] carried out the recycling of rare-earths from phosphor lamps after acid leaching of the phosphor powders using $\mathrm{N}$, $\mathrm{N}$-dioctyldiglycolamic acid (DODGAA) dissolved in the ionic liquid $\left[\mathrm{C}_{4} \mathrm{mim}\right]\left[\mathrm{NTf}_{2}\right]$ and compared with PC-88A (2-ethylhexylphosphonic acid mono-2-ethylhexyl ester) dissolved in dodecane. The results disclosed better separation and extraction efficiency between rare-earth and transition metals using DODGAA-IL system at $30{ }^{\circ} \mathrm{C}$ in sulphate media. Rout and Binnemans [47] described similar behaviour when a trihexyl(tetradecyl)phosphonium $\mathrm{N}, \mathrm{N}, \mathrm{N}^{\prime}, \mathrm{N}^{\prime}$-tetra(2ethylhexyl)malonate/trihexyl (tetradecyl) phosphonium nitrate $\left[\mathrm{P}_{66614}\right][\mathrm{MA}] /\left[\mathrm{P}_{66614}\right]\left[\mathrm{NO}_{3}\right]$ system was used in nitric solutions at $\mathrm{pH} 4$.

Sang et al. [48] investigated the separation of $\mathrm{Ce}^{3+}$, $\mathrm{Nd}^{3+}, \mathrm{Sm}^{3+}, \mathrm{Dy}^{3+}$ and $\mathrm{Yb}^{3+}$ from nitric acid solutions with a mixture of $0.1 \mathrm{~mol} / \mathrm{L}$ DEHPA dissolved in $\left[\mathrm{C}_{4}\right.$ $\operatorname{mim}]\left[\mathrm{PF}_{6}\right],\left[\mathrm{C}_{2} \mathrm{mim}\right]\left[\mathrm{PF}_{6}\right]$ and $\left[\mathrm{C}_{4} \mathrm{mpy}\right]\left[\mathrm{PF}_{6}\right]$ at $40{ }^{\circ} \mathrm{C}$. They found that for $0.01 \mathrm{~mol} / \mathrm{L}$ solution of $\mathrm{Ln}^{3+}$, the system had a high affinity for $\mathrm{Yb}^{3+}$. Rout et al. [49] carried out the separation of $\mathrm{La}^{3+}, \mathrm{Ce}^{3+}, \mathrm{Pr}^{3+}, \mathrm{Nd}^{3+}, \mathrm{Yb}^{3+}$ and $\mathrm{Y}^{3+}$ at trace level from nitrate solutions at $\mathrm{pH} 2$ using $\left[\mathrm{C}_{6} \mathrm{mim}\right][\mathrm{DEHP}] /\left[\mathrm{C}_{6} \mathrm{mim}\right]\left[\mathrm{NTf}_{2}\right]$ and $\left[\mathrm{C}_{6} \mathrm{mpyr}\right][\mathrm{DEHP}] /$ $\left[\mathrm{C}_{6} \mathrm{mpyr}\right]\left[\mathrm{NTf}_{2}\right]$ systems, and noticed that the light rareearths $\mathrm{La}^{3+}$ and $\mathrm{Ce}^{3+}$ were poorly extracted, meanwhile, $\mathrm{Nd}^{3+}$ and $\mathrm{Yb}^{3+}$ were strongly extracted, with $\operatorname{Pr}^{3+}$ being a borderline case. A similar observation was made by Yang et al. [50] when they carried out the separation of $\mathrm{Nd}^{3+}$, $\mathrm{Eu}^{3+}$ and $\mathrm{Dy}^{3+}$ with 5-octyloximethyl-8-quinolinol (HO8Q) in $\left[\mathrm{C}_{8} \mathrm{mim}\right]\left[\mathrm{NTf}_{2}\right]$ as the extracting phase.

\subsection{Solvent extraction processes applied for the recovery of scandium}

Derivation, preparation, purification, enrichment, and separation of scandium from its resources, which are typically non rare-earth minerals, are almost always achieved by employing solvent extraction processes [9]. Conventional solvent extraction processes for scandium recovery use a number of extractants including acidic organophosphorous extractants, such as TBP, D2EHPA, 2-ethylhexyl phosphonic acid mono-2-ethylhexyl ester (lonquest 801) and di2,4,4-trimethylpentyl phosphinic acid (Cyanex 272) for near-complete scandium extraction from sulphuric acid solutions. Typically, D2EHPA is used to extract scandium as Sc(III) and TBP subsequently used for preparation of high purity Sc(III) product. The TBP extraction step usually requires a high extracting aqueous acidity in the region of $10 \mathrm{~mol} / \mathrm{L} \mathrm{HCl}$. Li and Wang [52] showed that Cyanex 923 had a high $\mathrm{Sc}(\mathrm{III})$ extraction ability and could be directly used in waste liquor from $\mathrm{TiO}_{2}$ white pigment for scandium recovery. A summary of some of the investigations on scandium recovery is presented in Table 2 .

Despite the use of ILs in extraction processes starting to gain momentum, little research has been done on their use in scandium extraction in solvent extraction processes.

\subsection{Solvent extraction processes applied for the recovery of niobium and tantalum}

Commonly, columbite and tantalite are highly stable and can only be decomposed by digestion with concentrated hydrofluoric acid or its mixtures with sulphuric acid [8]. $1.2-2.5 \mathrm{t}$ of $70 \% \mathrm{HF}$ per ton of concentrate produced can be consumed depending on the $\mathrm{Nb}_{2} \mathrm{O}_{5}: \mathrm{Ta}_{2} \mathrm{O}_{5}$ and $\mathrm{FeO}$ : $\mathrm{MnO}$ ratios and the processing conditions. Other problems associated with this technology are the evaporation losses of $6 \%-7 \%$ (volume ratio) of $\mathrm{HF}$ during decomposition at $250{ }^{\circ} \mathrm{C}$, the prohibitively high recovery costs and the equipment maintenance [54-59]. During acid digestion, water soluble fluorides and oxy-fluorides are formed depending on the amount of free HF. For values lower than $35 \%$, the predominant species are $\mathrm{NbOF}_{n}^{3-n}$ and $\mathrm{TaOF}_{n}^{3-n}$, where $n$ ranges among 3-6, when the HF excess overcomes $35 \%$, the oxy-fluorides decompose to $\mathrm{NbF}_{m}^{5-m}$ and $\mathrm{TaF}_{m}^{5-m}$ fluorides [60, 61].

These fluorinated compounds readily combine with the organic molecules of the extraction agent to form extractable complexes. Only methyl-isobutyl ketone (MIBK) and TBP have been used in industrial processes [62].

MIBK can completely separate tantalum from niobium when the composition of the aqueous phase is $3 \mathrm{~mol} / \mathrm{L} \mathrm{HF}$ and $2 \mathrm{~mol} / \mathrm{L} \mathrm{H}_{2} \mathrm{SO}_{4}$. For higher concentrations of sulphuric acid, Okada [63] reported simultaneous extraction of both metallic ions. Agulyansky [64] related this phenomenon with the stronger Lewis acidity of niobium complexes, which requires strongest acid conditions in order to be extracted. Iron, titanium, manganese, aluminium, etc., are the common impurities associated with niobium and tantalum ores. It has been observed that the use of binary acid systems improves the separation factors between $\mathrm{Nb}$, Ta and the impurities according to the following sequence: $\mathrm{HF}-\mathrm{HNO}_{3}>\mathrm{HF}-\mathrm{H}_{2} \mathrm{SO}_{4}>\mathrm{HF}-\mathrm{HCl}>\mathrm{HF}$ [65].

Similarly to MIBK extraction, tantalum can be separated from niobium in $\mathrm{HF}-\mathrm{H}_{2} \mathrm{SO}_{4}$ systems using TBP, however, when the concentrations of $\mathrm{HNO}_{3}, \mathrm{HCl}$ and $\mathrm{H}_{2} \mathrm{SO}_{4}$ are high, the extraction efficiency of niobium decreases to levels too low for economic commercial extraction. Separation from other impurities however becomes more efficient for $\mathrm{HF}$ and $\mathrm{HF}-\mathrm{H}_{2} \mathrm{SO}_{4}$ systems [66]. 
Table 2 Effectiveness of typical extractants on scandium extraction

\begin{tabular}{|c|c|c|c|c|}
\hline References & Extractants & $\begin{array}{l}\text { Scandium } \\
\text { recovery } / \%\end{array}$ & $\begin{array}{l}\text { Scandium } \\
\text { purity } / \%\end{array}$ & Comments \\
\hline$[51]$ & $\begin{array}{l}\text { TBP followed by di(1-methyl } \\
\text { heptyl) mythyl phosphate }\end{array}$ & 93 & 99.995 & $\begin{array}{l}\text { Initially } 99 \% \text { Sc. } 2 \text { circuits are used. } \\
12 \text { carbons: } 266.32 \mathrm{~g} / \mathrm{mol}\end{array}$ \\
\hline$[52]$ & Cyanex 923 and Cyanex 925 & 94 & 95 & $\begin{array}{l}\text { Cyanex } 923 \text { is superior and is claimed better than TBP and HDEHP. } \\
\text { CYANEX } 923 \text { extractant is a mixture of four trialkylphosphine } \\
\text { oxides. Average MW is } 348 \mathrm{~g} / \mathrm{mol} \text {. }\end{array}$ \\
\hline$[53]$ & D2EHPA/TBP & 99 & - & $\begin{array}{l}0.05 \mathrm{~mol} / \mathrm{L} \text { DEHPA }+0.05 \mathrm{~mol} / \mathrm{L} \mathrm{TBP} \\
16 \text { carbons: } 322.43 \mathrm{~g} / \mathrm{mol}\end{array}$ \\
\hline$[54]$ & Amberlight AL-1 and AL-2 & 99.80 & - & $\begin{array}{l}\text { Diluents have significant effect. } \\
14 \text { carbons: } 213.4 \mathrm{~g} / \mathrm{mol}\end{array}$ \\
\hline$[55]$ & $\begin{array}{l}\text { di(2ethylhexyl)dithiophoshate } \\
\text { (Phoslex DT-8) in } n \text {-hexane }\end{array}$ & 97 & - & $\begin{array}{l}\text { No } \mathrm{Zr} \text { is extracted. } \\
16 \text { carbons: } 354.55 \mathrm{~g} / \mathrm{mol}\end{array}$ \\
\hline
\end{tabular}

There is no evidence in the literature about the use of ILs as solvent extraction agents for the separation of niobium and tantalum. However, some research regarding their individual electro-deposition from ILs has been carried out [67-70].

\subsection{Solvent extraction processes applied for the recovery of vanadium}

Vanadium can be extracted from neutral, acidic or basic solutions by solvent extraction processes [71]. Some of the relevant studies are presented in Table 3.

At an industrial scale, TBP, D2EHPA and amines are the established solvents for recovery of vanadium $[75,76]$. Zhao et al. [77] developed a process that employed solvent extraction using the ILs tricaprylmethylammonium nitrate ([A336][NO3]) and organic acidified primary amine N1923 ([RNH3][NO3] for successful separation of vanadium from chromium. Their study showed potential for application of the ionic liquid system in recovery of vanadium from industrial effluents, however there was no established commercial process that manipulated ILs as solvents for vanadium extraction.

\section{Liquid membranes}

Membranes are being widely recognized as key separation technologies and have a very important place in chemical technology where they are used in a broad range of applications such as water purification and recovery of precious metals [78]. Their key property, which also makes them unique in separation processes, is their ability to control the permeation rate of the metal species through the membrane [79]. The two typical transport processes are cation transport and anion transport.

Regardless of transport mechanism, charge neutrality should be maintained. Both cationic and anionic transport processes occur in four similar stages.

(i) At the phase I interface of the membrane, the guest salt is complexed with the carrier.

(ii) The complex diffuses across the membrane.

(iii) The release of that guest salt occurs at Phase II interface of membrane.

(iv) The carrier diffuses back across the membrane ready to continue.

A diagrammatic illustration of the ion transport through a liquid membrane is shown in Fig. 8.

Any of the four stages of cationic or anionic transport processes can influence the rate of ion separation through the membrane. The stage with the highest resistance to ion flow is the rate controlling stage and is typically the step both chemists and engineers work on to maximise mass transport across the membrane. For a diffusion based membrane system, membrane permeability is determined by:

Table 3 Effectiveness of different extractants on vanadium extraction

\begin{tabular}{lllll}
\hline References & Extractants & Vanadium recovery/\% & Vanadium purity/\% & Comments \\
\hline$[70]$ & D2EHPA/TBP & 97.7 & - & 16 carbons: $322.43 \mathrm{~g} / \mathrm{mol}$ \\
{$[71]$} & D2EHPA & 99 & 99.2 & $16 \mathrm{carbons:} 322.43 \mathrm{~g} / \mathrm{mol}$ \\
{$[72]$} & $10 \%$ P204, 5\% TBP & 85 & 99.52 & $12 \mathrm{carbons:} 266.32 \mathrm{~g} / \mathrm{mol}$ \\
{$[73]$} & EHEHPA & 99.9 & - & $16 \mathrm{carbons:} 306.23 \mathrm{~g} / \mathrm{mol}$ \\
{$[74]$} & Cyanex 272 & 60.5 & - & $16 \mathrm{carbons:} 290.42 \mathrm{~g} / \mathrm{mol}$ \\
\hline
\end{tabular}


$\frac{K D_{m}}{L}$

From the formula, we can deduce that to increase permeability and selectivity of a specie across the membrane, the distribution coefficient $(K)$ has to be increased where possible, membrane thickness $(L)$ decreased and membrane diffusion coefficient $\left(D_{m}\right)$ increased [80]. Complexing the species to go across the membrane with carrier ion decreases the diffusion coefficient value due to the increase in particle size, however, the value of the distribution coefficient is increased by many orders of magnitude, resulting in facilitated transport [80]. Carrier molecules which can selectively facilitate the movement of desired molecules across the membrane without significantly lowering the diffusion coefficient are at the forefront of ionic liquid membranes research.

They can allow a single type of metal ions in a multimetal ion solution to permeate the membrane freely while hindering permeation of other metal ions. There are several types of membrane separation processes being developed and the supported liquid membranes (SLMs) have shown huge potential in several applications. SLM consists of porous supports with a solvent impregnated inside the pores. Both organic solvents and ILs can be used in SLM, however, ILs have the advantage that they have a near-zero vapour pressure. They also have good chemical and thermal stabilities, having near-zero vapour pressures over a large temperature range [81, 82].

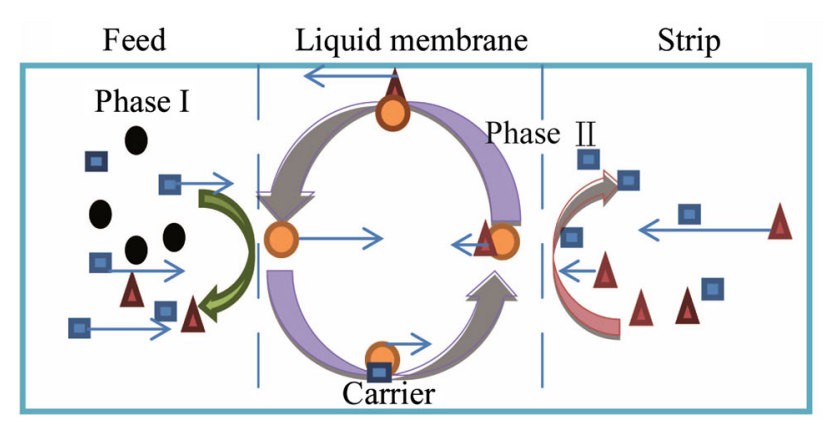

(a) Facilitated coupled counter-transport

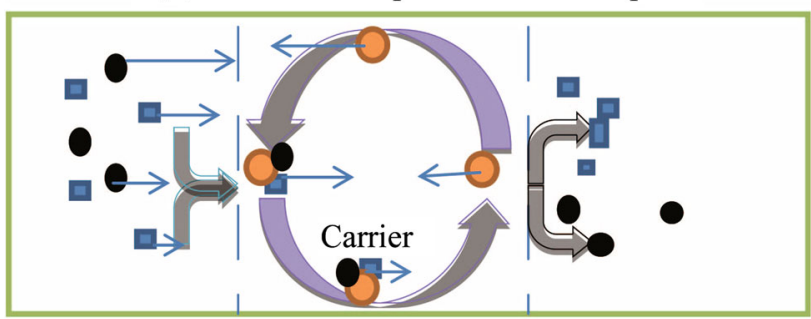

(b) Facilitated coupled co-transport

Fig. 8 Facilitated coupled transport of ions through liquid membrane [80]

\subsection{Liquid membranes in the separation of rare-earths}

The potential for application of membranes, particularly the SLMs, in separation and purification of REE has been extensively investigated over the last two decades [83-88]. Usage of ILs in liquid membranes however only started getting interest in the last decade and has not yet been established for commercial exploitation [89-91]. Kubota et al. [90] developed a stable ILs based membrane for separation of rare-earth metals. Their membrane quantitatively transported $\mathrm{Y}$ and Eu successfully, achieving a good separation from $\mathrm{Zn}$ using N,N-dioctyldiglycolamic acid (DODGAA) as the mobile carrier.

\subsection{Liquid membranes in the separation of scandium}

Although potential for liquid membrane usage in scandium separation has been researched as far back as the mid 1990s [92], it has not yet been exploited. Yang et al. [92] investigated the effectiveness of electrostatic pseudo liquid membrane (ESPLIM) in pre-concentrating and separating scandium from rare-earths, aluminium and iron and found that scandium could be purified from an aqueous solution of $2.3 \%$ to nearly $96 \%$ in a single separation stage.

\subsection{Liquid membranes in the separation of niobium and tantalum}

TBP based liquid membrane processes have been studied for separation of niobium from aqueous solutions, however there is no established commercial technology for the processes [93, 94]. Campderrós and Marchese [94] studied the transportation of niobium (V) through a TBP-alamine 336 supported liquid membrane from chloride solutions and found that the process was selective for niobium and could be used for effective separation of niobium from tantalum. Buachuang et al. [95] successfully removed tantalum from a solution of tantalum and niobium using a hallow fiber supported membrane, with aliquat-336 diluted in kerosene as a carrier, providing an effective separation of the two. The use of ionic liquid membranes for niobium and tantalum separation and purification has however not been studied extensively and there are currently no industrial scale processes for separation of niobium by ionic liquid membranes.

\subsection{Liquid membranes in the separation of vanadium}

Recovery of vanadium by liquid membranes has been studied extensively over the past decade. Palet et al. [96] 
recommended use of liquid membranes for removal of low concentrations $\left(10^{-6}\right)$ of vanadium from aqueous solutions. Chaudry et al. [97] investigated the effectiveness of tri- $n$ octyl amine cyclohexane SLMs in transporting vanadium and concluded that it was efficient for transportation of $\mathrm{V}$ ions. Yadav and Mahajani [98] recommended the use of liquid emulsion membrane processes as an alternative to the conventional processes employed for separation and purification of vanadium. Nosrati et al. [99] studied the transportation of vanadium from a feeding phase to an ammonia based stripping phase using the ionic liquid tri-noctyl methyl ammonium chloride (TOMAC) impregnated in PTFE support membrane and found the transportation very effective. They also found that vanadium was selectively transported from its mixture with chromium ions when TOMAC was used as the carrier.

\section{Barriers and opportunities}

ILs have great potential for revolutionising extraction processes due to their unique physical and chemical properties, however, a variety of challenges need to be addressed before ILs can be established as an alternative to conventional solvents at an industrial scale. The cost of a solvent is among the top factors taken into consideration when selecting a solvent for solvent extraction process [100]. It therefore follows that solvent losses should be minimised as high solvent losses can easily make an extraction process uneconomical. ILs have a negligible vapour pressure at temperatures below $100{ }^{\circ} \mathrm{C}$, which decreases the solvent losses, nevertheless, the ILs cost has been an important drawback for their industrial development. However, the major cost associated with adopting ILs is the cost of the ionic liquid itself not the investment required to produce them. The economy of scale works in ILs, and their production in tons scale will decrease their prices by several orders of magnitude, making them competitive with traditional organic solvents [101].

There are usually many candidate solvents for extraction of any particular metal, therefore, as well as the solvent cost, consideration has to be given as follows:

(i) Selectivity. The ability to remove and concentrate the metal solute from other metals present in the aqueous solution is desirable. ILs can be developed with specific applications in mind to match or even better the conventional organic solvents in separation and purification of valuable metals. They have been shown to be superior to conventional solvents for removal of metals such as strontium from aqueous nitrate solutions [102]. Since their properties, including selectivity, can be tailored by changing the cation or anion, development of highly selective ILs should be achievable with adequate research.

(ii) Solvent safety. Development of highly selective ILs alone is not enough. Considerations have to be given to such issues as toxicity, corrosiveness and flammability of the solvent candidates. Toxic solvents would require special measures to be taken for health considerations of plant employees and for purity of the extracted metals, depending on final use. Corrosive solvents may require expensive materials of construction for the extraction process. ILs currently being developed minimise problems associated with the environmentally unacceptable solvents that have been in use over the last century. Although ILs are generally considered safer than conventional organic solvents due to their low flammability and non-volatile nature, there are very few corrosion and toxicity data available in literature and such information is critical when developing safe commercial processes.

(iii) Solvent handling properties. Density, viscosity and vapour pressure are also key engineering considerations when deciding on solvents to use for metal extraction processes. As IL is a relatively new technology, there is inadequate information on the physical properties relevant to both the handling and process design. They are however certainly highly viscous, hence high solvent regeneration and circulation rates are not easily achievable. The typically high viscosities of ILs also impede both mass transfer and capacity while a low interfacial tension solvent may lead to emulsion problems and affect the rate of mass transfer between the phases. A density difference that is too small can result in separation problems, lower capacity and larger equipment while a density difference that is too big may make it difficult to obtain the drop sizes required for efficient extraction. In view of this, process engineers and chemists need to work together in developing industrially viable ILs.

(iv) Solvent solubility in the raffinate phase. High solvent solubility in the raffinate may lead to high solvent losses unless steps are taken to prevent such losses [100]. ILs have been shown to have low solubilities in typical raffinate phases [103], and if water-soluble, their recovery from raffinate phases is a relatively simple process since they can easily be recovered by water washing the raffinate. 
Using ILs, these properties can be tailored for specific applications when the right combination of cation and anion is selected. During the last decade, many research efforts have been carried out to address physical properties, corrosion and toxicity data [104, 105]. However, ILs and conventional organic solvents have been used as sole extraction agents, in mixtures IL-organic extractant, diluted in organic solvents or in other compatible ILs. This heterogeneity in the extraction systems which also involves differences in equilibration time, extraction temperature, initial $\mathrm{pH}$, concentration of the extraction agent and metallic ions load in the aqueous phase, make difficult their comparison and the determination on how the structure of the extraction agent affects the recovery of the metal ions.

Another key consideration that needs to be made when deciding on the best solvent is the miscibility of the two solvent with the feed. If the solvent is miscible in the feed, there usually is a need for either recovery of the solvent from the raffinate or continuous and costly replacement of the solvent.

The ease of solvent recovery also makes a key consideration to make. The solvent needs to be as pure as possible following stripping of the solute in order to permit recycling to the extractor and minimise losses and potential pollution [100]. Complexity of the solvent recovery operation is largely dependent on the mutual solubility of the two liquids (aqueous and solvent phases). Nearly immiscible solvents are generally preferred due to the ease associated with their clean-up, while partly miscible liquids may require expensive and complex unit operations such as extractive distillation for separation of the two phases. More research is required to investigate the stripping, recycle cycle and how to efficiently remove ILs from aqueous streams in order to avoid their introduction to the environment [106].

Since ILs are relatively new, there is limited literature on physical properties such as solubilities, heat capacities and viscosities, corrosion data as well as data on toxicity of ILs, making their commercialisation very challenging. Some ILs contain halogenated anions such as $\mathrm{BF}_{4}$, which despite being air stable and neutral [102], can undergo hydrolysis making them less favourable at an industrial scale, leading to a need for research into alternative ILs which can match the halogenated anion's selectivity and cost. Development of ILs for most applications has been done by chemists and this may be one of the overlooked barriers to commercialisation of the technology. There is a need for both engineers and scientists to collaborate during the research and development stages in order to minimise risk associated with scale up and ensure that industrially relevant ILs are developed. Key areas of research and development where scientists and engineers can work together can be summarised as: (i) Determination of physical properties, corrosion data and toxicity of ILs; (ii) Development of reliable thermodynamic models of phase behaviour; (iii) Recycling and reuse of ILs - development of ILs that can be recycled or reused to minimise costs; (iv) Scalability of the technology from laboratory scale to pilot plant and large scale commercial scale.

The aforementioned areas of research will not only improve the cost effectiveness of ILs but will also open up opportunities for usage of ILs in other industries such as chemical processing, pharmaceuticals, microelectronics and textiles industries, where non-volatile liquids with a wide liquidus range could work better and potentially reduce emissions and pollution [101].

Acknowledgments The authors acknowledge the financial supports from a consortium UK industry and the EPSRC standard grants (GR/ T19889/01 and GR/L95977/01) and PhD studentships for research which was initiated in 1997 at the University of Leeds. A. Jha also wishes to acknowledge the support from the European Union's Marie Curie Fellowship grant for Dr Sanchez-Segado.

Open Access This article is distributed under the terms of the Creative Commons Attribution 4.0 International License (http://crea tivecommons.org/licenses/by/4.0/), which permits unrestricted use, distribution, and reproduction in any medium, provided you give appropriate credit to the original author(s) and the source, provide a link to the Creative Commons license, and indicate if changes were made.

\section{References}

1. European Commission (2014) Critical raw materials for the EU. Available from http://ec.europa.eu/enterprise/policies/raw-mate rials/files/docs/report-b_en.pdf. Accessed 28 Sept 2014

2. Nuss P, Eckelman M (2014) Life cycle assessment of metals: a scientific synthesis. PLoS One 9(7):e101298

3. Koltun P, Tharumarajah A (2014) Life cycle impact of rareearth elements. ISRN Metall 2014:1-10

4. Massari S, Ruberti M (2013) Rare-earth elements as critical raw materials: focus on international markets and future strategies. Resour Policy 38(1):36-43

5. International Union of Pure and Applied Chemistry (IUPAC) (2005) Nomenclature of inorganic chemistry. RSC Publishing, Cambridge

6. Gupta C, Krishnamurthy N (2005) Extractive metallurgy of rareearths. CRC Press, Boca Raton

7. Jordens A, Cheng Y, Waters K (2013) A review of the beneficiation of rare earth element bearing minerals. Miner Eng 41:97-114

8. Habashi F (1997) Handbook of extractive metallurgy. Wiley$\mathrm{VCH}$, Weinheim

9. Wang W, Pranolo Y, Cheng C (2011) Metallurgical processes for scandium recovery from various resources: a review. Hydrometallurgy 108(1-2):100-108

10. Wagh A, Pinnock W (1987) Occurrence of scandium and rareearth elements in Jamaican bauxite waste. Econ Geol 82(3):757-761

11. Ochsenkühn-Petropulu M, Lyberopulu T, Parissakis G (1994) Direct determination of lanthanides, yttrium and scandium in bauxites and red mud from alumina production. Anal Chim Acta 296(3):305-313 
12. International Lead and Zinc Study Group, International Nickel Study Group and International Copper Study Group (2013) Study of by-products of copper, lead, zinc and nicke. Available from https://connect.innovateuk.org/documents/2865354/38954 67/Study+of+By-Products+of+Copper,\%20Lead,\%20Nickel +\%26+Zinc/2703f24f-14c6-4038-abb4-fb4f215327c6. Accessed 27 Apr 2015

13. United Nations Environment Programme (UNEP) International Resource Panel (2011) Recycling rates of metals: a status report

14. Binnemans K, Jones P, Blanpain B et al (2013) Recycling of rare-earths: a critical review. J Clean Prod 51:1-22

15. Pohl W (2011) Economic geology. Wiley-Blackwell, Chichester

16. Siirama L (2009) The Sokli mine project. Fennoskandian mining and exploration congress. Fennoskandian Mining and Exploration Congress, Rovaniemi

17. Zelikman A, Krěn O, Samsonov G (1966) Metallurgy of rare metals: metallurgiva redkikh metallov. Jerusalem: Israel program for scientific translations. Available from the U S Dept. of Commerce, Clearinghouse for Federal Scientific and Technical Information, Springfield

18. British Geological Survey (BGS) (2011) Mineral profile: niobium-tantalum. British Geological Survey, Nottingham

19. US Geological Survey (USGS) (2014) Mineral commodity summaries 2014: US Geological Survey, p 196

20. Dewhurst P (2013) Molybdenum and vanadium: key metals in titanium alloys. Roskill consulting group Ltd

21. US Geological Survey (2013) Mineral commodity summaries 2013: US Geological Survey, $198 \mathrm{p}$

22. Rydberg J (2004) Solvent extraction principles and practice. M. Dekker, New York

23. Wellens S (2014) Ionic liquid technology in metal refining: dissolution of metal oxides and separation by solvent extraction. Dissertation, KU Leuven Belgium

24. Izgorodina E, Bernard U, Dean P et al (2009) The madelung constant of organic salts. Cryst Growth Des 9(11):4834-4839

25. Laus G, Bentivoglio G, Schottenberger $\mathrm{H}$ et al (2005) Ionic liquids: current developments, potential and drawbacks for industrial applications. Lenzinger Berichte 84:71-85

26. Tian G, Li J, Hua Y (2010) Application of ionic liquids in hydrometallurgy of nonferrous metals. Trans Nonferr Metals Soc China 20(3):513-520

27. Regel-Rosocka M, Wisniewski M (2011) Ionic liquids in separation of metal ions from aqueous solutions. In: Handy S (ed) Applications of ionic liquids in science and technology. InTech, pp 375-398

28. Pham TPT, Cho CW, Yun YS (2010) Environmental fate and toxicity of ionic liquids: a review. Water Res 44(2):352-372

29. Ventura SPM, Marques CS, Rosatella AA et al (2012) Toxicity assessment of various ionic liquid families towards Vibrio fischeri marine bacteria. Ecotoxicol Environ Saf 76(2): 162-168

30. Xie F, Zhang TA, Dreisinger D et al (2014) A critical review on solvent extraction of rare earths from aqueous solutions. Miner Eng 56(2):10-28

31. Shimojo K, Kurahashi K, Naganawa H (2008) Extraction behavior of lanthanides using a diglycolamide derivative TODGA in ionic liquids. Dalton Trans 252(37):5083-5088

32. Jensen M, Neuefeind J, Beitz J et al (2003) Mechanisms of metal ion transfer into room-temperature ionic liquids: the role of anion exchange. J Am Chem Soc Jacs 125(50):15466-15473

33. Zuo Y, Liu Y, Chen J et al (2008) The separation of cerium(IV) from nitric acid solutions containing thorium(IV) and lanthanides(III) using pure $\left[\mathrm{C}_{8}\right.$ mim $] \mathrm{PF}_{6}$ as extracting phase. Ind Eng Chem Res 47(7):2349-2355
34. Belova VV, Voshkin AA, Egorova NS et al (2010) Extraction of rare earth metals from nitrate solutions with a binary extractant based on Cyanex 272. Russ J Inorg Chem 55(4):629-633

35. Rout A, Venkatesan KA, Srinivasan TG et al (2012) Ionic liquids extractans in molecular diluents: extraction behaviour of europium(III) in quaternary ammonium-based ionic liquids. Sep Purif Technol 95(7):26-31

36. Valdés-Vergara M, Lijanova I, Likhanova NV et al (2015) Recycling and recovery of ammonium-based ionic liquids after extraction of metal cations from aqueous solutions. Sep Purif Technol 155:110-117

37. Sun X, Ji Y, Guo L et al (2011) A novel ammonium ionic liquid based extraction strategy for separating scandium from yttrium and lanthanides. Sep Purif Technol 81(1):25-30

38. Castillo J, Coll MT, Fortuny A et al (2014) Cu(II) extraction using quaternary ammonium and quaternary phosphonium based ionic liquid. Hydrometallurgy 141(2):89-96

39. Li D, Wang Z, Song W et al (1994) Recommended separation processes for ion-absorbed rare earth minerals. Hydrometallurgy 94:627-634

40. Preston JS, Cole PM, Craig WM et al (1996) The recovery of rare earth oxides from a phosphoric acid by-product. Part 1: leaching of rare-earth values and recovery of a mixed rare-earth oxide by solvent extraction. Hydrometallurgy 41(1):1-19

41. Preston JS, Cole PM, du Preez AC et al (1996) The recovery of rare-earth oxides from a phosphoric acid by-product. Part 2: the preparation of high-purity cerium dioxide and recovery of a heavy rare-earth oxide concentrate. Hydrometallurgy 41(1): 21-44

42. Preston JS, du Preez AC, Cole PM et al (1996) The recovery of rare-earth oxides from a phosphoric acid by-product. Part 3: the separation of the middle and light rare-earth fractions and the preparation of pure europium oxide. Hydrometallurgy 42(2):131-149

43. Reddy MLP, Prasada RT, Damodaran AD (1993) Liquid-liquid extraction processes for the separation and purification of rare earths. Miner Process Extr Metall Rev 12(2-4):91-113

44. Sato T (1989) Liquid-liquid extraction of rare-earth elements from aqueous acid solutions by acid organophosphorus compounds. Hydrometallurgy 22(1-2):121-140

45. Sun X, Luo H, Dai S (2012) Solvent extraction of rare-earth ions based on functionalized ionic liquids. Talanta 90(1):132-137

46. Yang F, Kubota F, Baba Y et al (2013) Selective extraction and recovery of rare earth metals from phosphor powders in waste fluorescent lamps using an ionic liquid system. J Hazard Mater 254-255:79-88

47. Rout A, Binnemans K (2014) Liquid-liquid extraction of europium(III) and other trivalent rare-earth ions using non-fluorinated functionalized ionic liquid. Dalton Trans 43(4):1862-1872

48. Sang JY, Lee JG, Tajima H (2010) Extraction of lanthanide ions from aqueous solution by bis(2-ethylhexyl)phosphoric acid with room-temperature ionic liquids. J Ind Eng Chem 16(3):350-354

49. Rout A, Kotlarska J, Dehaen W et al (2013) Liquid-liquid extraction of neodymium(III) by dialkylphosphate ionic liquids from acidic medium: the importance of the ionic liquid cation. Phys Chem Chem Phys 15(39):16533-16541

50. Yang F, Kubota F, Kamiya N et al (2013) Extraction of rareearth ions with an 8-hydroxyquinoline derivative in an ionic liquid. Solv Extr Res Dev, Jpn 20:123-129

51. Zhang P, You S, Zhang L et al (1997) A solvent extraction process for the preparation of ultrahigh purity scandium oxide. Hydrometallurgy 47(1):47-56

52. Li D, Wang C (1998) Solvent extraction of scandium(III) by Cyanex 923 and Cyanex 925. Hydrometallurgy 48(3):301-312 
53. Wang W, Pranolo Y, Cheng YC (2013) Recovery of scandium from synthetic red mud leach solutions by solvent extraction with D2EHPA. Sep Purif Technol 108(16):96-102

54. Dalvi MB, Khopkar SM (1979) Solvent extraction of scandium from malonic acid with high molecular-weight amines. Talanta 26(9):892-894

55. Fujinaga K, Yoshimori M, Nakajima Y et al (2013) Separation of $\mathrm{Sc}$ (III) from $\mathrm{ZrO}$ (II) by solvent extraction using oxidized Phoslex DT-8. Hydrometallurgy 133(2):33-36

56. Zhou HM, Yi DQ, Zhang Y et al (2005) The dissolution behaviour of $\mathrm{Nb}_{2} \mathrm{O}_{5}, \mathrm{Ta}_{2} \mathrm{O}_{5}$ and their mixture in highly concentrated $\mathrm{KOH}$ solution. Hydrometallurgy 80(1-2):126-131

57. Zhou H, Zheng S, Zhang Y (2005) Leaching of a low-grade niobium-tantalum ore by highly concentrated caustic potash solution. Hydrometallurgy 80(1-2):83-89

58. Wang XH, Zheng SL, Xu HB et al (2010) Dissolution behaviours of $\mathrm{Ta}_{2} \mathrm{O}_{5}, \mathrm{Nb}_{2} \mathrm{O}_{5}$ and their mixture in $\mathrm{KOH}$ and $\mathrm{H}_{2} \mathrm{O}$ system. Trans Nonferr Metals Soc China 20(10):2006-2011

59. Yang XL, Wang XH, Wei C et al (2013) Decomposition of niobium ore by sodium hydroxide fusion method. Metall Mater Trans B 44(1):45-52

60. Packer KJ, Muetterties EL (1963) Nature of viobium(V) fluoride species in solution. J Am Chem Soc 85(19):3035-3036

61. Baumann EW (1972) Investigation of the tantalum fluoride system using the fluoride-selective electrode. J Inorg Nucl Chem 34(2):687-695

62. Zhu Z, Cheng CY (2011) Solvent extraction technology for the separation and purification of niobium and tantalum: a review. Hydrometallurgy 107(1-2):1-12

63. Okada T (2001) Manufacturing of special niobium oxides for optical and ceramic applications. In: International symposium on niobium, pp 175-183

64. Agulyansky A (2004) The chemistry of tantalum and niobium fluoride compounds. Elsevier, Amsterdam, pp 339-340

65. Nishimura S, Moriyama J, Kushima I (1964) Behaviors of Sn, Ti and $\mathrm{Fe}$ in liquid-liquid extraction of $\mathrm{Nb}$ and $\mathrm{Ta}$. Trans Jpn Inst Met 5(1):32-38

66. Nishimura S, Moriyama J, Kushima I (1964) extraction and separation of tantalum and niobium by liquid-liquid extraction in the HF-H2SO4-TBP system. Trans Jpn Inst Met 5(1):39-42

67. Giridhar P, Abedin SZE, Bund A et al (2014) Electrodeposition of niobium from 1-butyl-1-methylpyrrolidinium bis(trifluoromethylsulfonyl)amide ionic liquid. Electrochim Acta 129(16):312-317

68. Mascia M, Vacca A, Mais L et al (2014) Electrochemical deposition of $\mathrm{Cu}$ and $\mathrm{Nb}$ from pyrrolidinium based ionic liquid. Thin Solid Films 571:325-331

69. Maho A, Delhalle J, Mekhalif Z (2013) Study of the formation process and the characteristics of tantalum layers electrodeposited on nitinol plates in the 1-butyl-1-methylpyrrolidinium bis(trifluoromethylsulfonyl)imide ionic liquid. Electrochim Acta 89(1):346-358

70. Babushkina OB, Ekres S (2010) Spectroscopic study of the electrochemical behaviour of tantalum(V) chloride and oxochloride species in 1-butyl-1-methylpyrrolidinium chloride. Electrochim Acta 56(2):867-877

71. Alibrahim M, Shlewit H, Alike S (2008) Solvent extraction of Vanadium (IV) with di(2-ethylhexyl) phosphoric acid and tributyl phosphate. Period Polytech Chem Eng 52(1):29-33

72. Li X, Deng Z, Wei C et al (2015) Solvent extraction of vanadium from a stone coal acidic leach solution using D2EHPA/ TBP: continuous testing. Hydrometallurgy 154:40-46

73. Hu G, Chen D, Wang L et al (2014) Extraction of vanadium from chloride solution with high concentration of iron by solvent extraction using D2EHPA. Sep Purif Technol 125(14): $59-65$
74. Deng ZG, Wei C, Fan G et al (2010) Extracting vanadium from stone-coal by oxygen pressure acid leaching and solvent extraction. Trans Nonferr Met Soc China 20(S1):s118-s122

75. Jayadas S, Reddy ML (2002) Solvent extraction separation of vanadium(V) from multivalent metal chloride solutions using 2-ethylhexyl phosphonic acid mono-2-ethylhexyl ester. J Chem Technol Biotechnol 77(10):1149-1156

76. Li X, Wei C, Wu J et al (2012) Thermodynamics and mechanism of vanadium(IV) extraction from sulphate medium with D2EHPA, EHEHPA and CYANEX 272 in kerosene. Trans Nonferr Met Soc China 22(2):461-466

77. Zhao J, Hu Q, Li Y et al (2015) Efficient separation of vanadium from chromium by a novel ionic liquid-based synergistic extraction strategy. Chem Eng J 264:487-496

78. Cui Z, Muralidhara H (2010) Membrane technology. Elsevier/ Butterworth-Heinemann, Oxford

79. Scott K (1995) Handbook of industrial membranes. Elsevier Advanced Technology, Oxford

80. Kocherginsky NM, Yang Q, Seelam L (2007) Recent advances in supported liquid membrane technology. Sep Purif Technol 53(2):171-177

81. Lozano LJ, Godínez C, Ríos APDL et al (2011) Recent advances in supported ionic liquid membrane technology. J Membr Sci 376(1-2):1-14

82. Ríos APDL, Hernández-Fernández FJ, Lozano LJ et al (2013) On the selective separation of metal ions from hydrochloride aqueous solution by pertraction through supported ionic liquid membranes. J Membr Sci 444(1):469-481

83. Yang XJ, Gu ZM, Fane AG (1999) Multicomponent separation by a combined extraction/electrostatic pseudo-liquid membrane (II): extraction and group separation of rare earths from simulated rare-earth ore leach solutions. Hydrometallurgy 53(1):19-29

84. Yaftian MR, Burgard M, Dieleman CB et al (1998) Rare-earth metal-ion separation using a supported liquid membrane mediated by a narrow rim phosphorylated calix[4]arene. J Membr Sci 144(1-2):57-64

85. Zhu LL, Guo L, Zhang ZJ et al (2012) The preparation of supported ionic liquids (SILs) and their application in rare metals separation. Sci China Chem 55(08):1479-1487

86. Wannachod T, Leepipatpiboon N, Pancharoen U et al (2014) Separation and mass transport of $\mathrm{Nd}(\mathrm{III})$ from mixed rare earths via hollow fiber supported liquid membrane: experiment and modeling. Chem Eng J 248:158-167

87. Nakayama C, Uemiya S, Kojima T (1995) Separation of rare earth metals using a supported liquid membrane with DTPA. J Alloy Compd 225(1-2):288-290

88. Chitra KR, Gaikwad AG, Surender GD et al (1997) Studies on ion transport of some rare-earth elements through solvating extractants immobilised on supported liquid membrane. J Membr Sci 125(2):257-268

89. Yang F, Kubota F, Baba Y et al (2013) Selective extraction and recovery of rare earth metals from phosphor powders in waste fluorescent lamps using an ionic liquid system. J Hazard Mater 254(12):79-88

90. Kubota F, Shimobori Y, Koyanagi Y et al (2010) Uphill transport of rare-earth metals through a highly stable supported liquid membrane based on an ionic liquid. Anal Sci Int J Jpn Soc Anal Chem 26(3):289-290

91. Baba Y, Kubota F, Kamiya N et al (2011) Recent advances in extraction and separation of rare-earth metals using ionic liquids. J Chem Eng Jpn 44(10):679-685

92. Yang XJ, Gu ZM, Wang DX (1995) Extraction and separation of scandium from rare-earths by electrostatic pseudo liquid membrane. J Membr Sci 106(1-2):131-145 
93. Campderrós ME, Marchese J (2010) Facilitated transport of niobium $(\mathrm{V})$ and tantalum( $(\mathrm{V})$ with supported liquid membrane using TBP as carrier. J Membr Sci 164(99):205-210

94. Campderrós ME, Marchese J (2001) Transport of niobium(V) through a TBP-Alamine 336 supported liquid membrane from chloride solutions. Hydrometallurgy 61(2):89-95

95. Buachuang D, Ramakul P, Leepipatpiboon N et al (2011) Mass transfer modeling on the separation of tantalum and niobium from dilute hydrofluoric media through a hollow fiber supported liquid membrane. J Alloy Compd 509(39):9549-9557

96. Palet C, Muñoz M, Hidalgo M et al (1995) Transport of vana$\operatorname{dium}(\mathrm{V})$ through a tricaprylylmethylammonium solid supported liquid membrane from aqueous acetic acid/acetate solutions. J Membr Sci 98(3):241-248

97. Chaudry MA, Bukhari N, Mazhar M (2007) Vanadium(V) ions transport through tri- $n$-octyl amine cyclohexane supported liquid membranes. Sep Purif Technol 54(2):227-233

98. Yadav SV, Mahajani VV (2007) Liquid emulsion membrane (LEM) process for vanadium (IV) enrichment: process intensification. Sep Sci Technol 42(6):1283-1303
99. Nosrati S, Jayakumar NS, Hashim MA et al (2013) Performance evaluation of vanadium (IV) transport through supported ionic liquid membrane. J Taiwan Inst Chem Eng 44(3):337-342

100. Albright L (2009) Albright's chemical engineering handbook. CRC Press, Boca Raton, pp 709-715

101. Brennecke JF, Maginn EJ (2001) Ionic liquids: innovative fluids for chemical processing. AIChE J 47(11):2384-2389

102. Khupse ND, Kumar A (2010) Ionic liquids: new materials with wide applications. Indian J Chem 49(5-6):635-648

103. Letcher $\mathrm{T}$ (2007) Thermodynamics, solubility and environmental issues. Elsevier, Amsterdam

104. Atkins MP, Davey P, Fitzwater G et al (2004) Ionic liquids: a map for industrial innovation. Report Q001, January 2004. QUILL, Belfast

105. Fitzwater G, Geissler W, Moulton R et al (2005) Ionic liquids: sources of innovation, report Q002. QUILL, Belfast

106. Chemical Industry Vision 2020 Technology Partnership (2004) Accelerating ionic liquid commercialization. Research Needs to Advance New Technology, pp 1-40 